\title{
Narrative Medicine - the methodology of doctor-patient communication analysis
}

\author{
Ioana Silistraru ${ }^{1 *}$ \\ ${ }^{1}$ University of Bucharest, Romania, Faculty of Sociology and Social Work, 9 Schitu Măgureanu Street, 050064 - \\ Bucharest, Romania.
}

\section{KEYWORDS}

Communication

Empathy

Illness

Narrative medicine

\section{A BSTRACT}

The present paper aims at presenting a non-exhaustive list of methodology instruments for narrative analysis in medical communication. Patient narratives became of more and more importance while evidence-based medicine has created a gap between patients, their illness and their doctors. While being investigated through hightechnology instruments used in medicine, the patient vanishes behind the computer screen where his body is analysed based on the biomedical factors. Narrative medicine is defined by one of its founders as the interaction between a health practitioner who doesn't simply look at diseases, but treats the person who's suffering from an illness by listening closely to his story (Charon 2001). Therefore, as mentioned by Rita Charon in her works, the doctor-patient interactions are measured considering the effectiveness of medical care. The patient is empowered with medical knowledge related to his illness, transposed into an accessible language. On the other side of the communication spectrum, the doctor reconnects with his patient, manifesting interest on how the patient's life is affected by illness, not only on how it can be effectively treated. 'Now, in recent years medical narrative is changing - from the stories about patients and their illnesses, patient narratives and the unfolding and interwoven story between healthcare professionals and patients are both gaining momentum, leading to the creation or defining of narrative-based medicine (NBM).' (Kalitzkus and Matthiessen 2009). Narrative based medicine is presented to counteract the pitfalls of evidence-based medicine (EBM). NBM can foster a better care while taking into account the patient's story on the

* Contact address: ioana.silistraru@icloud.com (I. Silistraru). 
way illness is affecting the quality of his everyday life. The final objective of effective medical care is to alleviate, if not to dismiss completely the illness and the suffering of the patients.

\section{Introduction}

The narrative is defined as a linguistic unit by a number of specific traits. Firstly, the narrative is limited, as unfolds on the temporal axis. Therefore, it starts at the beginning with the unfolding events, usually narrated by the author's voice and it has a predictable ending, at least from a temporal point of view. Secondly, once we note the involvement of at least one narrator and one receptor, the way the story unfolds is affected by the differences in perception and vision of both participants over the narrated events. Thirdly, according to Greenhalgh and Hurwitz (1999), the narrative is individual centred, by illustrating how he, the individual, is impacted by the events. Therefore, the simple narration of the events, as the unfold consecutively it is not enough to build a story, but what the character does or what happens to him during the events, it is equally important for the narrative. The value of context offered by the narrative resides in presenting the methods of solving real illness associated problems, reported by patients. Fear, anxiety, despair, pain, shame or sadness - they all come together with the illness the patients are suffering, usually enhancing the illness's effects (Greenhalgh and Hurwitz 1999, 48).

\section{Theoretical framework}

\section{Narratives in a medical discourse context}

While interacting with patients, young doctors are taught in medical school to obtain as much clinical information as possible from them. The information is helping doctors to come with a diagnosis, in some cases a differential one. Anamnesis textbooks consist of hundreds and hundreds of 
questions regarding the physical body of the patient, defined as a sum of functioning or malfunctioning internal organs. In this framework, the doctor is supposed to gather as much information as possible, enabling him to produce an accurate diagnosis, while the patient's role is limited to offering this information. Nevertheless, last decades of medical practice brought to light the necessity of changing the type of medical interview applied to patients. Lazare, Putnam and Lipkin Jr. (Lazare, Putnam, and Lipkin 1995) have organized the existing concepts around three functions, which are desired to be fulfilled during a medical interview: 'determine and monitor the problem; develop, maintain and conclude the therapeutic relationship; and carry out patient education and implementation of treatment plan.' (Lazare, Putnam, and Lipkin 1995, 3).

Narrative medicine offers answers to today's medical practice while being caught up in its growth as a science, medicine forgot that it is an art, and, as any other art, it must celebrate the birth of a story (Ofri 2006). Therefore, the medicine will seek more and more literary answers. The scientific literature has known lately a booming rise in the number of illness stories, both from patients and doctors. The aim is to counteract to the dehumanizing effects of technology development in medical sphere (Thernstrom 2004).

\section{Medical practice in need of reform}

"The good physician treats the disease; the great physician treats the patient who has the disease." (Sir William Osler)

The predominant passive role of the patient is underlined by Lazare, Putnam and Lipkin in the paper 'Three Functions of the Medical Interview' (Lazare, Putnam, and Lipkin 1995, 18). The authors even suggest replacing the expression of 'taking the history' (or the equivalent of anamnesis process) with 'interview', coming from 'inter' (between) and 'view' (vision, to see), which better suits the doctor-patient communication through shared 
ideas and thoughts. The suggestions are justified by the position of the medical practitioner, who is taking the information from the patient, setting the latter in a passive position of a 'giver'. In the meantime, the doctor's role is limited to processing the only information the patient is willing to offer. The latter has, according to Lazare, Putnam and Lipkin $(1995,18)$, the possibility of withholding and camouflaging some information, if he wishes to do so. The word 'interview' on the other hand is a much better choice, underlining the active status of both doctor and patient, participating in the dialogue.

According to Robert Centor (2007), the distinction between the good doctor and a great doctor is in his own capacity for understanding the full story of a patient:

'Each patient represents a story. That story includes their diseases, their new problem, their social situation, and their beliefs.

How do we understand the story? We must develop excellent communication skills and gather the history in appropriate depth. We must perform a targeted physical examination based on the historical clues. We must order the correct diagnostic tests, and interpret them in the context of the history and physical exam. Once we collect the appropriate data, we then should construct that patient's story.

The story includes making the correct diagnosis or diagnoses. The story must describe the patient's context. Who is this patient? What are the patient's goals? How might the patient's personal situation impact our treatment options?

Sir William Osler said, "The good physician treats the disease; the great physician treats the patient who has the disease." The great physician understands the patient and the context of that patient's illness.

For you, physician readers, take Osler's challenge. Be a great physician. Understand the full story. Make the correct diagnoses. Consult the patient in designing the treatment plans that best fit that patient.' (Centor 2007). 
Medical communication is of pivotal importance in the effective medical care

'Medical communication is at the heart of medicine. Without good communication, neither a diagnosis nor a treatment plan can be established.' (de Haes and Bensing 2009)

Young doctors usually learn by imitation, following closely the way their professors communicate with their patients. While in medical school, students have little independence, therefore there is a finite set of skills they borrow from their teachers, from direct observation (de Haes and Bensing 2009).

Narrative medicine, after becoming academic research and teaching field in recent years, was started by Rita Charon, at Columbia University. Being a doctor, with a $\mathrm{PhD}$ degree in English literature, with a thesis on Henry James's work, Charon has established the narrative medicine school, pointing out that the main quality of the discipline is basically that it can be taught, transmitted and absorbed as a particular skill by medical students. Communication studies within the medical field are meant to help doctors organize his discourse during their interaction with the patient, bringing important clarification regarding the efficiency of patient-doctor dialogue (de Haes and Bensing 2009).

\section{Effective medical communication}

The whole purpose of effective medical communication according to Rita Charon (2004) is to form an 'efficient therapeutic alliance', presumably with equal communication space in between the two actors (or more, if members of the patient's family are involved in the communication process). According to Halpern, what was once considered an additional educational 'layer' for a doctor - which is getting acquainted with literature, being familiar with humanities, describing in a literary way the medical practice - 
it is acknowledged today as a central pillar of practising medicine with empathy and reflection (Halpern 2001).

\section{Methods}

\section{Discourse analysis method - RIAS}

RIAS (Roter Interaction Analysis System) has been developed by the team led by sociologist Debra Roter, based on social interactions theories, interpersonal influence, reciprocity and problem-solving theories. RIAS has been used widely as a doctor-patient dialogue coding system in the US, Europe, Asia, Africa and Latin America. It offers, in Debra Roter's opinion some advantages over other systems:

'RIAS shows advantages over other systems in four ways: it is practical, functional, flexible, and methodologically sound, with an established record of good reliability and demonstrated predictive validity to a variety of patient and provider outcomes and discriminatory sensitivity to varying medical context.' (Roter and Larson 2002).

The Roter's system is defined in 'Slicing it thin: New methods for brief sampling analysis using RIAS-coded medical dialogue' (Roter et al. 2011):

'The RIAS is a widely used quantitative coding system for patient-physician communication that has demonstrated reliability and predictive validity. The unit of analysis is the smallest speech segment conveying a thought to which a classification may be assigned. This may vary in length from a single word to a lengthy sentence. The system assigns each statement expressed by the patient and physician to 1 of 37 mutually exclusive categories of communication that relate broadly to the instrumental and affective dimensions of the visit.' (Roter et al. 2011, 411).

The systems offer a mutually exclusive and exhaustive framework of categories to be used in analysing the content of the doctor-patient 
interaction. The system itself it has its pitfalls, which are described by Roter herself:

"Just because a variable can be measured does not necessarily mean that it can provide meaning; conversely, failing to adequately capture a phenomenon does not mean that it lacks significance." (Roter and Larson 2002).

The communication with a patient is centred on tasks and objective, referring to two out of the three functions of medical interview (Lazare, Putnam, and Lipkin 1995), therefore one of the most encountered forms of doctor-patient communication. While interviewing the patient, the doctor will follow at least two objectives - to gather information, enabling him to better understand the patient's condition, and to educate him, offering the patients all the information he needs to understand his own condition. Once the patients have the necessary information to understand his condition, the main objective is to get his compliance with the treatment plan. The emotional approach in the course of doctor-patient communication generates a separate category of information, regarding the third function of the medical interview, which is creating a bond, developing a rapport between the doctor and his patients, which eventually facilitates the response to the patient's emotions (Roter and Larson 2002).

Roter and Larson will identify the fourth function of the medical interview, targeted at 'partnership development' between the doctor and the patient, a form of verbal communication, with the purpose of facilitating the integration, synthesis and the mobility between the biomedical discourse and the psycho-social paradigms, owned by the patient before engaging with the healthcare practitioner. In other words, one effective medical communication would include the availability of doctors to explain medical data, so the patient will assimilate information for which he is not specifically trained for:

'Activation strategies (e.g. asking for the patient opinion, asking for understanding, paraphrase and interpretation) facilitate the expression of patients' expectations, preferences, and perspectives so that they may more meaningfully participate in 
treatment and management decision-making.' (Roter and Larson 2002).

The advantages of RIAS coding, conversational analysis and teaching those results to medical students have been demonstrated by the improvement of communication skills (Roter et al. 2004). The study 'Use of an innovative video feedback technique to enhance communication skills training' (Roter et al. 2004) researched the improvement of communication skills in 28 of residents, which took part in simulated and video recorded interviews. Coding the conversation through RIAS system is possible, with proper training, without any full prior transcription. Each full sentence, idea or just meaningful word, said by the doctor or by the patient, will be coded with one of the 38 predetermined categories, exclusive and exhaustive. The predefined categories are related to social and emotional functions (expressing and responding to emotion, positive-negative, social exchanges and active building of partnership). The coding categories are also related to the purpose of the medical interview (education, counselling on medical aspects of the illnesses, treatment plan, lifestyle, psycho-social elements). The abovementioned study, researching the communication skills in medical residents followed three mail categories, closely related to the doctor's availability in solving a problem raised by a patient; conversational probing to solve a problem 'do you think there is a different solution to your problem?'; assistance to solving a problem 'do you thinks that a two-months prescription would help you stock on your medicine?'; partnership and support 'if you have any other questions or if I could help you with anything else, do not hesitate to call'.

The purpose of the study 'Use of an innovative video feedback technique to enhance communication skills training' (Roter et al. 2004) was to prove that through conversational analysis, the medical interview can be upgraded at least in four directions: to listen more/to talk less; to gather information through open-ended questions to patients, whose answers will provide in-depth information regarding his lifestyle, his preferences, perceptions and psycho-social issues; to improve the way the family 
members present are addressed during the medical encounter; to build an active doctor-patient partnership to ensure compliance to the prescribed treatment plan (Roter et al. 2004, 138).

Narrative medicine has been researched over three decades but still, the main dilemma regards its connection to evidence-based medicine:

'Nevertheless, the current debate is focused more on the dualism between Narrative Medicine and Evidence-Based Medicine: on the one hand medicine needs to be focused on scientificallyrigorous trials and to follow specific protocols, on the other hand, the final aim of medical practice is always related to what a patient feels, what they perceive they feel and above all, what they say they feel.' (Fioretti et al. 2016).

\section{Doctor-patient communication asymmetry}

Narrative-based medicine in a world dominated by evidence-based medicine enhances the gap already researched in the literature between the science of objective measurements and the art of analysis and clinical expertise (Greenhalgh 1999). The definition of narrative medicine offered by Trisha Greenhalgh is the following:

'The art of selecting the most appropriate medical maxim for a particular clinical decision is acquired largely through the accumulation of "case expertise" (the stories or "illness scripts" of patients and clinical anecdotes)'. (Greenhalgh 1999).

The asymmetry within the context of doctor-patient communication, according to (Richard and Lussier 2014) is distributed over four areas of context: psychological, relational, situational and sociocultural. Psychological factors show up in the very first discourse context - the actors are able to understand each other if they share the same set of personality defining traits - needs, values, attitudes, roles, images, self-esteem, knowledge and other similar traits: 
'These aspects shape the way one speaks and an awareness of these same aspects in the other person affects how one interprets what he or she says.' (Richard and Lussier 2014, 68).

Within the second, relational context, there is an inherent asymmetry of the doctor-patient relationship. According to (Richard and Lussier 2014) there is a concept of bi-directional, non-simultaneous 'domination'. The 'domination' depends on the context of the patient-doctor encounter, both engaged in an asymmetrical relationship.

'Here, we must underline the inherent asymmetry in the physician-patient relationship. However, the dominance in this asymmetry will vary within the larger context of the encounter and within different moments of a specific physician-patient meeting. In the larger context, patients may be seen as dominating the relationship both before and after the specific encounter: for example (1) the patient is, most often, the one to decide to seek help; and (2) the patient is the one to decide to implement the treatment. In the specific encounter context, there is also some variability; for example, patients may dominate the talk about their medical problems and their medical history in the first segment of the encounter, but usually physicians will dominate in the third segment, in which the physician explains the diagnosis and shares the plan for investigation and treatment.' (Richard and Lussier 2014, 68).

This relationship asymmetry is analysed with patients suffering from dementia narratives. According to Abraham M. Nussbaum (2016), while trying to reproduce a patient's story, no matter how accurate the story might be reproduced, with all illnesses details, it doesn't eventually belong to the patient, but to the doctor. Nussbaum will point out the difference between an accurate diagnosis and the real help a patient gets from his doctor:

'I tried to be the author who gathered the seemingly disparate strands of her story into a single compelling narrative, a story called dementia. The story was accurate, but it was a medical story, not Eleanor's story. I saw pathology, a broken part, and while I was correct in my diagnosis, I wonder whether I did her a disservice. My diagnosis led directly to her giving up wine, which she loved, and to her moving to a nursing home, which 
she hated. By naming her "demented," I left her diminished.' (Nussbaum 2016).

In his work 'The Finest Tradition of my Calling: One Physician's Search for the Renewal of Medicine' (2016), Nussbaum will present the idea of a completely new asymmetry, apart from the one frequently encountered with doctors and their patients, engaged in medical dialogue. While referring to the case of the patient named Eleanor, suffering from dementia in an advanced stage, the doctor recalls how the first of his measures was to scrupulously go through all steps of medical protocol, dictated by the evidence-based medicine - tests, more tests, reactions, clinical evaluations, medical explanations on progressive and irreversible deterioration of patient's condition, eventually on her death. The doctor himself notes that the only option with that patient, after checking out all the necessary steps required in biomedicine, is to accompany the patient through his sufferance, offering him not just a medical diagnosis, but an 'assistant', a 'skipper', to guide the patient through his illness. This kind of repositioning of the doctor, moving away from the dominating and patriarchal figure, to a guiding and accompanying figure, one will find in Rita Charon's work 'Narrative Medicine: A Model of Empathy, Reflection, Profession, and Trust' (2001). Charon defines this transformation as follows:

'With narrative competence, physicians can reach and join their patients in illness, recognize their own personal journeys through medicine, acknowledge kinship with and duties toward other health care professionals, and inaugurate consequential discourse with the public about health care. By bridging the divides that separate physicians from patients, themselves, colleagues, and society, narrative medicine offers fresh opportunities for respectful, empathic, and nourishing medical care.' (Charon 2001, 1897). 


\section{Discussion}

\section{Real communication skills}

According to Bird and Cohen-Cole in 'The Three Function Model of the Medical Interview,' there are numerous pieces of evidence that indicate a inadequacy of doctor-patient communication skills. The large majority of research studies at the beginning of the 90 s prove that medical discourse, the information the patient receives, are often useless or incomplete. The patient gets interrupted soon after 12-18 seconds of discourse, which ends up in a deficient collection of medical information, the data on his sufferance and the way he is touched by his illness are incomplete. Since his discourse is often and quickly interrupted, doctors fail in recognising psycho-social problems and mental illness. Bird and Cohen-Cole note in their study that doctors seem to fail in transmitting clear information to their patients, in a way that they will comply to the treatment plan (Bird and Cohen-Cole 1990, 67). According to the authors, the issue can be addressed with an appropriate communication training of future doctors. Rita Charon (Charon et al. 2016) mentions as a core quality of narrative medicine as an academic topic the way the communication skills can be taught to medical students. Narrative medicine can be taught as a set of skills to be applied in the medical field. Narrative competence is regarded by Charon (2004) as the set of skills required to recognize, absorb, interpret, and be moved by the stories one hears or reads:

This competency requires a combination of textual skills (identifying a story's structure, adopting its multiple perspectives, recognizing metaphors and allusions), creative skills (imagining many interpretations, building curiosity, inventing multiple endings), and affective skills (tolerating uncertainty as a story unfolds, entering the story's mood). Together, these capacities endow a reader or listener with the wherewithal to get the news from stories and to begin to understand their meanings." (Charon 2004).

The literature (Arora 2003; Fallowfield and Jenkins 1999; Berghammer, 
Dellborg, and Ekman 2006; Rosti 2017) mentions that one of the most meaningful in terms of patient-doctor interaction is the moment of diagnosis communication. Communicating a chronic disease diagnosis or a lifethreatening illness as cancer, the way this communication unfolds is one of the most significant interactions between a doctor and his patients. The way the patient receives a life-threatening diagnosis will define the future developments of his health status (Arora 2003). One inadequate communication from the doctor's side might produce a major discomfort to his patient and his family as well, while the family or friends will also expect to receive full and comprehensive information on the patient's condition and future developments of his diagnosed illness (Fallowfield and Jenkins 1999). Once a diagnosis is shared with a patient, the latter will be 'labelled' and the way this 'label' is communicated to the patient is important not just for the patient's rapport to his doctor, but also to his family and his social environment. This is one conclusion of the research study 'Young adults experiences of living with congenital heart disease' (Berghammer, Dellborg, and Ekman 2006), which shows that the majority of the participants, diagnosed with coronary diseases, would rather not share their diagnosis of 'heart disease', fear of being labelled as such, and friend and family will change their attitude towards them into pity. The outcome of the study, where surgical patients with coronary diseases, aged between 20 and 40 years old, shows that psycho-social adjustment (which depends mostly depends on the quality of the patient-doctor interactions, starting with diagnosis) is crucial to the further social integration of those patients, to the improvement of their post-diagnosis and post-surgery life quality (Berghammer, Dellborg, and Ekman 2006):

'Psychosocial adaptation has been shown to be an important and complex dimension in their perceived quality of life; they face many practical problems, such as finding a job, getting a driver's license or obtaining life insurance.' (Berghammer, Dellborg, and Ekman 2006).

The literature fully acknowledges that doctor-patient communication and communication directed to the patient's family and friends is of crucial 
importance (Rosti 2017). The narratives emerging from doctor-patient interactions, which belong either to the doctor, either to the patient or to the both of the participants at the communication act, are one of the most valuable diagnose instruments (Ofri 2017). In Ofri's opinion, this instrument is invaluable to the patient's future compliance with the treatment. Doctorpatient dialogue needs improvement - performing analysis to the communication skill sets of experienced doctors or early career medical practitioners proved that an adequate communication to the patient it helps not only the patient but the doctor as well, besides the organization he is performing his medical duties. Such an appropriate and effective doctorpatient communication, when the patient is backed up with relevant information on his disease, the effects, the therapeutic plan and the risks, it will consistently reduce the risk of malpractice accusations. The effect has been observed in the countries where health legislation is protecting the medical personnel with insurance policies (Huntington and Kuhn 2003):

'It is easy to blame insurance companies, plaintiff lawyers, and runaway juries for our woes. It is harder to examine our own practices and ask ourselves what we could do to change patients' feelings that they need to sue doctors, hospitals, and nurses. In this age of phenomenal technological innovations and highly successful treatments and cures, why is it that our customers, the patients, are dissatisfied with their health care to such a degree that they feel compelled to file a lawsuit?' (Huntington and Kuhn 2003).

Huntington and Kuhn (2003) will state that the inability to show compassion to patients, especially when a difficult diagnosis or a lifethreatening disease are communicated, will be perceived as an arrogance. One vicious circle of doctor-patient communication is set when results of failed tests or unwanted results are communicated to the patient without consideration to his feelings.

In certain situations, patients will go through a full range of emotions and feelings, especially on the negative side, the study shows. Facing a patient who expresses rage or frustration, a doctor without communication 
competence or with a low level of empathy will instantly react by closing down all communication channels and will end up avoiding his patient, being defensive, which eventually will be interpreted as arrogance and careless attitude by the patient himself. The consequences might be negative in a deficient cycle of communication, where neither the doctor nor the patient is able to manage the narrative and the emotions. Huntington and Kuhn (2003) would recommend doctors an action plan to communicate unwanted results and underline the importance of uninterrupted communication. This action plan will rely on the following turning points: recognize the patient's frustration and possible fear, recognize own feelings of disappointment and anxiety, do not panic and keep lines of communication open, express regret that the adverse result occurred but avoid finding fault or blaming others, explain what happened and the proposed plan of action in terms the patient can understand, keep the patient and family informed and involved in subsequent treatment plans and discussions; document the discussion in the medical record (Huntington and Kuhn 2003):

'In any situation, good physician-patient communication is the mainstay of a therapeutic, mutually respectful, and trusting relationship. The advice of treating each patient as you would want a close family member treated will give a physician all the guidance needed.' (Huntington and Kuhn 2003, 160).

One special category of authors writing about doctor-patient narratives consists of doctors becoming at some point patients or patients who have the necessary skills to write in a scientific manner about their experience with doctor-patient communication. Andrew McDonald (2016), a prostate cancer survivor describes how difficult patient-doctor dialogue is, even if the language is common. In 'What doctors say and what patients hear' (McDonald 2016) even the simplest medical statement is completely different understood by the patients, depending on their expectations, perceptions, cultural level or state of mind. McDonald would illustrate these differences through oncologist-patient communication, as his own experience proved. The phrase 'cancer survivor' is understood as 'person 
who was cured of cancer' by the patient, while the doctor refers to those patients who are still alive after five years from being diagnosed; 'in remission' is interpreted by the patient as 'I am not cured yet, but cancer will avoid me for some time', while the doctor will define remission as 'the absence of cancer in the patient's body for the time being'. The same way of reading applies to the pair 'benign-malign': while the doctor will declare a tumour as benign, he or she will refer to the mass as to 'a growth which develops at an uncontrollable speed, but which will not metastasize', while the patient will interpret the news as 'not really good, but I won't die because of this'. McDonald will conclude that the way we could completely erase such misunderstandings in medical communication is to drop off the metaphors while speaking about the illness and, ideally, the doctor and the patient will end up sharing a common language. This is what the author defines as an effective doctor-patient communication (McDonald 2016).

One definition of narrative medicine, but especially on what narrative medicine is not, it is provided by Giovanni Rosti in 'Role of narrative-based medicine in proper patient assessment' (2017). The author proves how VAS (Visual Analogue Scale, a scale used to measure elements usually escaping the measurement, such as pain threshold in patients), can be interpreted as an evaluation with hierarchizing objective or from the patient's perspective, as to measure the impact of the pain perceived by the patient.

The Rosti diagram shows how a patient's narrative could lead to faster and more accurate identification of the illness, as to a better solution to alleviate the pain. Narrative medicine is, therefore, able to provide increased accuracy to traditional methods, as VAS, in pain evaluation and treatment. A narrative analysis will bring an additional element - the impact the pain has on a patient's everyday life and activities, as well as the extent it impacts his quality of life. While using both techniques simultaneously - traditional pain evaluation and narrative analysis - health practitioners will be reminded constantly that pain belongs to an individual, not to an abstract entity (the patient), each and every patient being differently affected by the illness or its manifestations (Rosti 2017). 
Figure 1. VAS system in measuring the perception of pain

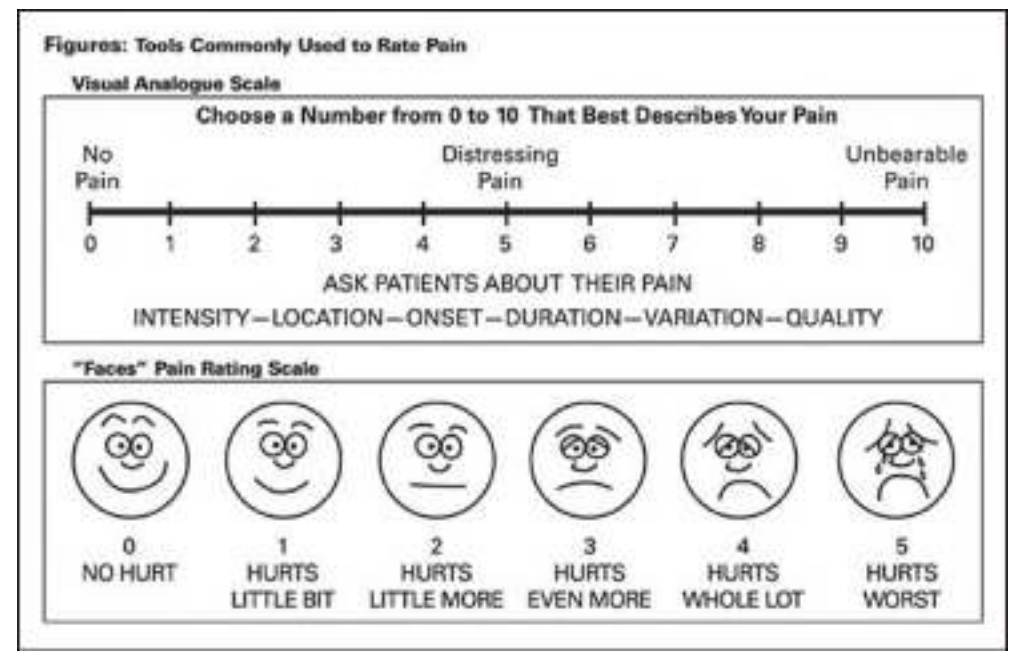

Source: Ghaderi et al. 2013, 791.

Figure 2. Narratives in evaluation of pain

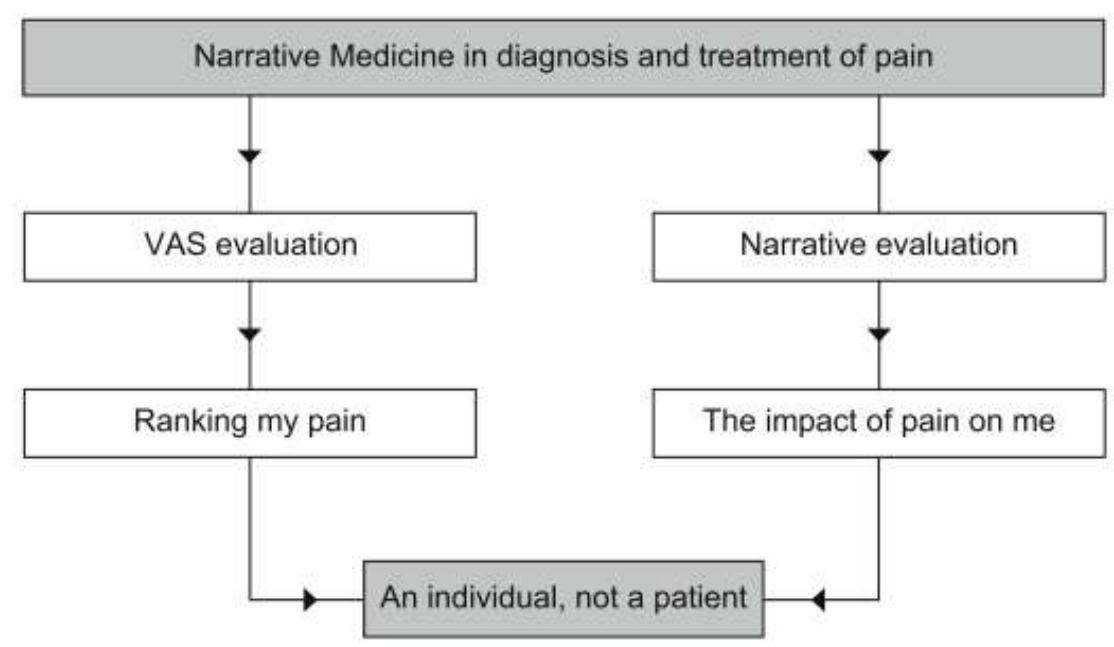

Source: Rosti 2017, S5.

The postmodern society is faced with one important consequence of developing technology in medicine - the patient is disappearing behind a 
computer screen. The physical body, the illness and the effects that have on the patient's quality of life - all concealed by biomedical elements which actually help to treat the illness - CT scans, radiology, ultrasound, computer monitored bodily functions (Blaxter 2009, 2). Therefore, the diagnosis is established far away from the patient himself, and further from his lifestyle changes due to the illness:

'Real diagnostic work takes place away from the patients; bedside is secondary to screen side. For diagnostic and even treatment purposes, the image of the screen becomes the "true" patient, of which the bedridden body is an imperfect replica, less worthy of attention. In the screens' simulations, our initial certainty of the real (the body) becomes lost in hyperreal images that are better than the real body (Frank 1992: 83).' (Blaxter 2009, 3).

\section{Soft-skills in medical communication}

The literature (Joubert et al. 2006; Charon 2001; Robertson and Clegg 2017; Younie 2009) defines the soft-skills as a set of social and interpersonal communication skills, comprising doctor-patient professional communication skills and general communication skills, which are professionally and ethically regulated. Developing this set of skills largely depends on personal availability and professional background of medical students. (Joubert et al. 2006). The fact that these skills can be directly transmitted and taught, makes them a more valuable asset in medicine (Charon 2001). Teaching narrative competence is the purpose of narrative medicine, a scientific field developed almost thirty years ago by the narrative medicine school at Columbia University. Narrative medicine is to bring into everyday practice those particular communication instruments, complementing the ones used by evidence-based medicine, to be able to gather, interpret and use the information on patients' experiences with the illness and sufferance (Charon 2006). Although from a unilateral perspective of the medical practitioner, who by the narrative competences definitions 
should be able to recognize, absorb and interpret the patient's narratives (Charon 2004, 862), owning the soft-skills is hardly uniform in the medical environment:

'In the UK and Europe, although there are some notable exceptions, medical education has lagged behind in this area. Many senior clinicians still view the ideas as woolly or selfindulgent 'soft-skills'. By contrast, in North America teaching in narrative competence is increasingly part of mainstream medical teaching.' (Clegg and Robertson 2017, 22).

Teaching narrative skills, as in activating narrative competences, it has been exposed in a mini-research in 2008, at Bristol University (Younie 2009). The research objective was that the participants will learn how to creatively describe their encounters with the patients. Therefore, an interview with a patient diagnosed with severe depression became an art piece, a painting named 'The Light at the End of the Tunnel'. The medical student who painted it, Amy, was also the one conducting the interview with a fifty-yearold patient, Mrs. Jones (the names used to denominate the patients were not the real ones). Amy, as noted in the article, will mention the fact that regardless of the dark visual representation, as the illness experience with depression is described during the interview, there is an optimistic moment (Younie 2009). The name of the painting is inspired by the interview with Mrs. Jones, as a medical student Amy says, as the patient confesses to his healthcare practitioner that someday she might beat depression:

'Creative and imaginative representations of patient narratives may afford learning that reaches parts other educational methods cannot, extending beyond the cognitive to a more holistic engagement of mind and heart. Amy.' (Younie 2009, 54). 
Figure 3. The light at the end of the tunnel

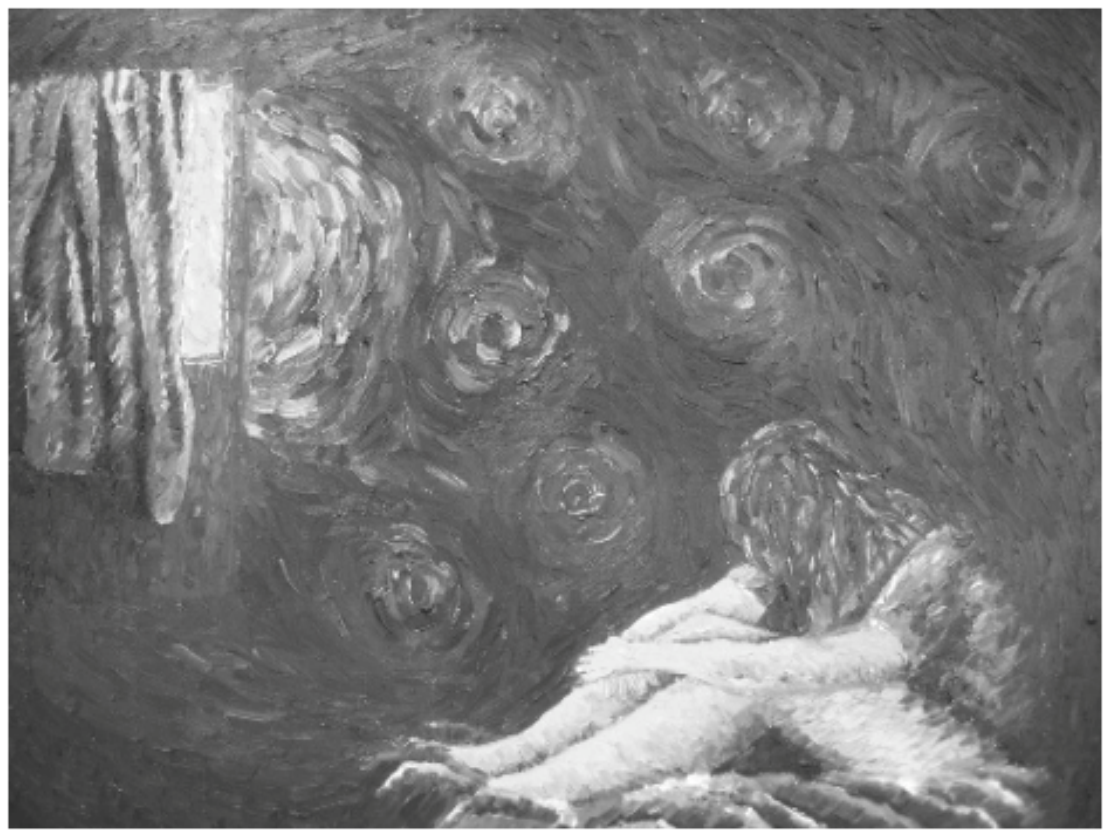

Note: Graphic representation of patient's narrative (Younie 2009, 55).

\section{Conclusions}

\section{Limitations of narrative medicine}

Narrative medicine does not aim to replace evidence-based medicine or biomedical explorations, therefore narrative skills are not meant to replace the ones of the medical science (Charon 2006, 12). Therefore its value as a science, as defined through the literature, is mainly educational and descriptive (Kalitzkus and Matthiessen 2009, 84). As from the perspective of applying the principles of narrative medicine, it is obvious that the technological advancement in medical practice will bring more clarity in terms of biomedical evaluation (Rosti 2017), although the patient will be drawn much further apart from his doctor (Blaxter 2009). The speed with which one patient can be evaluated these days through technology could actually provide more time for his doctor to analyse his illness narrative, 
offering a lot of free time to the doctor to apply narrative techniques during his interactions with his patients:

'While on one hand, an evidence-based approach is needed, it should also be kept in mind that the art of medicine involves applying knowledge to a single individual.'(Rosti 2017).

On the other hand, narrative skills are not a pre-existing condition in medicine, while applying the narrative medicine principles will require time and effort because 'significant technical and attitudinal change that is necessary does not come quickly' (Kalitzkus and Matthiessen 2009):

'The biggest challenge in taking a narrative approach is knowing when to stop. Disease, disability, deprivation, and death are not stories. They are facts. Professionals, who get carried away by narrative ideas to the point where they forget this, are not safe.' (Kalitzkus and Matthiessen 2009, 84).

\section{References}

Arora, Neeraj K. 2003. "Interacting with cancer patients: The significance of physicians' communication behavior". Social Science and Medicine 57(5): 791-806. doi:10.1016/S0277-9536(02)00449-5.

Berghammer, Malin, Mikael Dellborg, and Inger Ekman. 2006. "Young adults experiences of living with congenital heart disease". International Journal of Cardiology 110(3): 340-347. doi:10.1016/ j.ijcard.2005.08.006.

Bird, Julian and Steven A. Cohen-Cole. 1990. "The Three-Function Model of the Medical Interview". Advances in psychosomatic medicine 20: 65-88. doi:10.1159/000418260.

Blaxter, Mildred. 2009. "The case of the vanishing patient? Image and experience". Sociology of Health and Illness 31(5): 762-778. doi:10.1111/ j.1467-9566.2009.01178.x.

Centor, Robert M. 2007. "To be a great physician, you must understand the whole story." MedGenMed : Medscape general medicine 9(1): 59 .

Charon, Rita. 2001. "Narrative Medicine A Model for Empathy, Reflection, Profession, and Trust". JAMA 286 (15): 1897-1902. doi:10.1001/ jama.286.15.1897. 
Charon, Rita. 2004. "Narrative and medicine". New England Journal of Medicine 350(9): 862-864. doi:10.1056/NEJMp038249.

Charon, Rita. 2006. Narrative medicine: Honoring the stories of illness. New York: Oxford University Press.

Charon, Rita, Sayantani DasGupta, Nellie Hermann, Craig Irvine, Eric R Marcus, Edgar Rivera Colsn, Danielle Spencer, and Maura Spiegel. 2016. The Principles and Practice of Narrative Medicine. New York: Oxford University Press.

Clegg, Gareth, and Colin Robertson. 2017. Storytelling in medicine how narrative can improve practice. Boca Raton: CRC Press.

Fallowfield, Lesley and Val A. Jenkins. 1999. "Effective communication skills are the key to good cancer care". European Journal of Cancer 35(11): 1592-1597. doi:10.1016/S0959-8049(99)00212-9.

Fioretti, Chiara, Ketti Mazzocco, Silvia Riva, Serena Oliveri, Marianna Masiero, and Gabriella Pravettoni. 2016. "Research studies on patients' illness experience using the Narrative Medicine approach: a systematic review". BMJ Open 6(7): e011220. doi:10.1136/bmjopen2016-011220.

Ghaderi, Faezeh, Shahin Banakar, and Shima Rostami. 2013. "Effect of precooling injection site on pain perception in pediatric dentistry: 'A randomized clinical trial'". Dental Research Journal 10(6): 790-794.

Greenhalgh, Trisha. 1999. "Narrative based medicine: narrative based medicine in an evidence based world." BMJ (Clinical research ed.) 318(7179): 323-325. doi:10.1136/bmj.318.7179.323.

Greenhalgh, Trisha and Brian Hurwitz. 1999. "Narrative based medicine: why study narrative?" BMJ (Clinical research ed.) 318 (7175): 48-50. doi:10.1136/bmj.318.7175.48.

de Haes, Hanneke, and Jozien Bensing. 2009. "Endpoints in medical communication research, proposing a framework of functions and outcomes". Patient Education and Counseling 74(3): 287-294. doi:10. 1016/j.pec.2008.12.006.

Halpern, Jodi. 2001. From Detached Concern to Empathy: Humanizing Medical Practice. New York: Oxford University Press.

Huntington, Beth and Nettie Kuhn. 2003. "Communication gaffes: a root cause of malpractice claims". Baylor University Medical Centre Proceedings 16(2): 157-161.

Joubert, Pierre M., C. Kruger, A.-M. Bergh, G.E. Pickworth, C.W. Van Staden, J.L. Roos, W.J. Schurink, R.R. Du Preez, S.V. Grey, and B.G. Lindeque. 2006. "Medical students on the value of role models for developing «soft skills» - «That's the way you do it»". South African 
Psychiatry Review 9: 28-32. doi:10.4314/ajpsy.v9i1.30204.

Kalitzkus, Vera and Peter F. Matthiessen. 2009. "Narrative-based medicine: potential, pitfalls, and practice." The Permanente Journal 13(1): 80-86.

Lazare, Aaron, Samuel M. Putnam, and Mack Lipkin, Jr.. 1995. "Three Functions of the Medical Interview". In The Medical Interview Clinical Care, Education, and Research, edited by Mack Lipkin, Jr., Samuel M. Putnam, and Aaron Lazare 3-19. New York: Springer. doi:10.1007/ 978-1-4612-2488-4.

McDonald, Andrew. 2016. "What doctors say and what patients hear". BMJ (Clinical research ed.) 354: i4453. doi:10.1136/bmj.i4453.

Nussbaum, Abraham M. 2016. The Finest Traditions of My Calling: One Physician's Search for the Renewal of Medicine. New Haven: Yale University Press.

Ofri, Danielle. 2017. What patients say, what doctors hear. Audiobook. Boston: Beacon Press.

Ofri, Danielle. 2006. "The practice of medicine: neither science nor art". The Lancet 367 (9513): 807-808. doi:10.1016/S0140-6736(06)68320-7.

Richard, Claude and Marie-Thérèse Lussier. 2014. "The art of medical information exchange". In The Oxford Handbook of Health Communication, Behaviour Change, and Treatment Adherence, edited by Leslie R. Martin and M. Robin DiMatteo, 54-83. New York: Oxford University Press.

Rosti, Giovanni. 2017. "Role of narrative-based medicine in proper patient assessment". Supportive Care in Cancer 25: 3-6. doi:10.1007/s00520017-3637-4.

Roter, Debra L., Judith A. Hall, Danielle Blanch-Hartigan, Susan Larson, and Richard M. Frankel. 2011. "Slicing it thin: New methods for brief sampling analysis using RIAS-coded medical dialogue". Patient Education and Counseling 82(3): 410-419. doi:10.1016/j.pec.2010.11.019.

Roter, Debra L., Susan Larson, Harold Shinitzky, Robin Chernoff, Janet R. Serwint, Graceanne Adamo, and Larry Wissow. 2004. "Use of an innovative video feedback technique to enhance communication skills training". Medical Education 38(2): 145-157. doi:10.1111/j.13652923.2004.01754.x.

Roter, Debra and Susan Larson. 2002. "The Roter interaction analysis system (RIAS): Utility and flexibility for analysis of medical interactions". Patient Education and Counseling 46(4): 243-251. doi:10.1016/S07383991(02)00012-5.

Thernstrom, Melanie. 2004. "The Writing Cure". The New York Times, April, 18. Accessed February 18, 2018. http://www.nytimes.com/2004/ 
04/18/magazine/the-writing-cure.html (accessed 2.18.18).

Younie, Louise. 2009. "Developing narrative competence in medical students". Medical Humanities 35(1): 54. doi:10.1136/jmh.2008.001354. 